\title{
Long-term relationship between air and water temperatures in Lake Paldang, South Korea
}

\author{
Soon Ju Yu, In Gu Ryu, Min Ji Park, Jong Kwon Im $^{\dagger}$ \\ National Institute of Environmental Research, Han River Environment Research Center, 42, Dumulmeori-gil 68beon-gil, Yangseo-myeon, Yangpyeong-gun, \\ Gyeonggi-do, 12585, Republic of Korea
}

\begin{abstract}
A long-term investigation into the relationship between air and water temperatures was conducted in Lake Paldang, which is the largest water source in South Korea, by studying hysteresis. From 1973 to 2018, the annual mean air temperature increased by $0.05^{\circ} \mathrm{C} / \mathrm{yr}$ (seasonal Sen's slope). The results of a numerical model $(\mathrm{R}>0.86)$ showed that the ratios of the air and water temperatures increased $(0.71-0.77)$ in the rising limb and decreased $(0.70-0.76)$ in the falling limb. However, the intercept values were $0.13-3.52$ and $6.62-7.78$ in the rising and falling limbs, respectively, and hence there was a $4-5^{\circ} \mathrm{C}$ increase in temperature. In particular, in 2015, 2016, and 2018, the intercept values in the falling limb were $\geq$ 7, exhibiting hysteresis, whereby high water temperatures were slow to decline. Lake Paldang showed stronger water temperature hysteresis than its influent rivers and stream. The rising and falling limbs did not show a large difference in the extent of water temperature change (slope). However, the water temperature did not decrease rapidly, and the decrease continued for longer due to hysteresis, which is a type of inertia where the elevated temperature persists if the summer air temperature is significantly increased.
\end{abstract}

Keywords: Climate change, Lake Paldang, Numerical model simulation, Temperature hysteresis

\section{Introduction}

Global warming has been occurring since industrialization, and, especially in the late 20th century, numerous unprecedented climatic changes have been observed for the first time in decades or centuries [1]. For example, the mean air temperature has increased more rapidly over the last several decades than at any other time since the use of instrumental measurements [2, 3]. Additionally, during the last 138 years (1880-2017), 9 of the 10 highest global mean air temperatures have been recorded since 2000 [4]. Likewise, in South Korea, the highest annual air temperature since 1973 was recorded in 2016, the third highest was 2015, and the seventh highest was in 2017, clearly showing warming in recent years [5]. The surface water temperature of many lakes throughout the world has undergone rapid warming during recent decades [6-12]. It has been shown that lakes warming is, in some cases, greater than that observed for the surrounding air temperature [7], especially at mid latitudes including in North America and North Europe [9, 13].

Among several environmental changes caused by the climate, increased air temperatures affect the water cycle by increasing or

This is an Open Access article distributed under the terms of the Creative Commons Attribution Non-Commercial License (http://creativecommons.org/licenses/by-nc/3.0/) which permits unrestricted non-commercial use, distribution, and reproduction in any medium, provided the original work is properly cited.

Copyright (C) 2021 Korean Society of Environmental Engineers altering water temperatures, which causes changes in river ecosystems, water quality, and local weather [14-16]. This is because water temperature is one of the most important factors for physical, chemical, and biological properties of aquatic habitats [17], fish growth [18], spawning rates [19], and water quality [20]. Changes in water temperature that are secondary to increased air temperature are associated with alterations in the ability of species of fish and other aquatic organisms to adapt to changing environments, and also affect water quality, which governs biochemical reactions in water [21-23].

Water temperature changes are affected by several factors in addition to air temperature, such as radiant heat, the extent of obstacles shielding radiant heat, the temperatures of influent river water and groundwater from the basin, and heat transfer at the water surface. The effects of air temperature on water temperature differ by region and according to various other factors due to the physical characteristic of water having a higher specific heat than air $[24,25]$. Due to the effects of the specific heat of water, even if the air temperature decreases the decline in water temperature is delayed and occurs more slowly [26]. Seasonally, greater losses of latent heat occur in summer than in winter due to evaporation,

Received April 10, 2020 Accepted August 21, 2020

${ }^{\dagger}$ Corresponding author

E-mail: lim-jkjk@daum.net

Tel: +82-31-770-7240 Fax: +82-31-773-2268

ORCID: 0000-0003-3994-5127 
and other forms of air-water temperature relationships can manifest due to the influx of groundwater after the rainy season or the influx of snowmelt in spring [14, 27]. Therefore, when analyzing the relationship between air and water temperatures, it is important to consider seasonal hysteresis depending on whether it is the rising limb (that is, when the temperature increases from early spring to summer) or the falling limb (when the temperature decreases from late summer to winter).

Lakes differ from rivers in size and other characteristics, which lead to differences in hysteresis [28]. The water temperature of a lake is a result of a combination of complex thermodynamic flux [12]. Changes in the thermal behavior of lakes lead to significant consequences for stratification and mixing regimes [13] and in the community structure of many habitats [29], with possible modifications of the biochemical compositions of some algae species [30]. Especially in deep lakes, increasing air temperatures exacerbates the stratification that occurs mostly in summer and can create favorable conditions for cyanobacterial growth by decreasing dissolved oxygen (DO) levels in the deep-water layer and restricting vertical water movement [31, 32]. For many lakes, an increase in the surface water temperature in summer occurs in conjunction with an increase in the duration and intensity of the stratification period, with increased inhibition of vertical exchanges of mass, energy, and momentum between the epilimnion and hypolimnion [12]. Additionally, thermal stratification of lakes can intensify anoxia [33], increase bloom-forming cyanobacteria including toxic species in summer [34], and cause changes in internal nutrient loading and lake productivity [33, 35].

To evaluate an increasing water temperature in a lake, consecutive water and air temperature data are required. However, in Korea, the majority of observed water temperature data are not continuous measurements, but rather are taken at specific times [36]. Consequently, because they are not synchronized with air temperature measurements, it is not possible to accurately interpret how changes in the water temperature of a given water body relate to climate change. Therefore, predicting and understanding water temperature are desired goals, and models of different types and complexities have been proposed ranging from simple regression models [37] to more complex process-based numerical one-dimensional [38] and three-dimensional models [39]. Sharma et al. [37] developed models predicting annual maximum near-surface lake water temperature for lakes across Canada using four statistical approaches: multiple regression, regression tree, artificial neural networks, and Bayesian multiple regressions.

Lake Paldang, which is largest drinking water source in South Korea, is the sole source of tap water for 26 million people, representing half of South Korea's population. Therefore, conservation of water quality and the health of aquatic ecosystems in Lake Paldang are very important. In this study, we assessed the tendencies in the variations of long-term changes in air and lake water temperatures using the seasonal Mann-Kendal test and examined the effects of air temperature changes on water temperature in Lake Paldang, South Korea. In addition, the relationship between air temperature and water temperature was investigated, and we acquired daily mean water temperature data based on a numerical model and analyzed the effects of changes in air temperature on the water temperature of the lake as well as the hysteresis effect.

\section{Methods and Materials}

\subsection{Study Area}

Lake Paldang is the artificial reservoir created via the construction of the Paldang Dam in 1973. It is located at the upper stream of the Han River, South Korea. For the purpose of power generation and water supply for 26 million people including the citizens of the Seoul Metropolitan area, Lake Paldang is a very important water resource. Due to the importance of Lake Paldang, this watershed has been managed by a strict regulation plan to prevent water pollution. The volume of the lake is 244 million tons, and the watershed area is approximately $23,800 \mathrm{~km}^{2}$. The watershed area compared to the water surface area $\left(36.5 \mathrm{~km}^{2}\right)$ is very large and the average depth of the lake is around $6.5 \mathrm{~m}$. The residence time is very short, comparatively, such that it seems to be a stream-like reservoir.

\subsection{Analysis of Air and Water Temperature Trends at Lake Paldang Using the Mann-Kendall Test}

Daily mean air temperature data from the Yangpyeong Weather Station (Korea Meteorological Administration), which is the closest weather station to Lake Paldang, were used [40]. For water temperature, weekly data from the Paldang Dam (PD) site in front of Paldang Dam provided by the Water Environment Information System were used [41]. For long-term air temperature changes, temperatures from 1973 (i.e., when the Yangpyeong Weather Station meteorological data began to be revealed) until 2018 were compared. To analyze water temperature trends with changing air temperature in Lake Paldang, statistical analysis of the period from 2004-2018 was performed, during which time data were collected for both variables. In terms of techniques for statistical analysis, the widely used seasonal Mann-Kendall test [42, 43] was utilized to analyze annual trends in monthly mean temperature. The Mann-Kendall test [44, 45] was also used to analyze seasonal trends based on seasonal mean temperature (spring, summer, fall, and winter). The test is a non-parametric test commonly employed to detect monotonic trends in series of environmental, climate, or hydrological data. After performing the Mann-Kendall test for each season, unified trends were obtained by calculating the weighted sums, thereby excluding seasonality [42].

The Mann-Kendall statistics for the $g$ th season are calculated as $[44,45]$ :

$$
\begin{gathered}
S_{g}=\sum_{i=1}^{n-1} \sum_{j=i+1}^{n} \operatorname{sgn}\left(X_{j g}-X_{i g}\right), g=1,2, \ldots . ., m, \\
\operatorname{sgn}(x)=\left\{\begin{array}{c}
1 \text { if } x>0 \\
0 \text { if } x=0 . \\
-1 \text { if } x<0
\end{array}\right.
\end{gathered}
$$

The mean of $S$ is $\mathrm{E}[\mathrm{S}]=0$ and the variance $\sigma^{2}$ is:

$$
\sigma^{2}=1 / 18\left\{n(n-1)(2 n+5)-\sum_{j=1}^{p} t_{j}\left(t_{j}-1\right)\left(2 t_{j}+5\right)\right\},
$$

where $p$ is the number of the tied groups in the data set and $t_{j}$ is the number of data points in the $j$ th tied group. The statistic 
$S$ is approximately normally distributed, provided that the following Z-transformation is employed:

$$
\mathrm{Z}=\left\{\begin{array}{cl}
\frac{S-1}{\sigma} & \text { if } S>0 \\
0 & \text { if } S=0 \\
\frac{S+1}{\sigma} & \text { if } S<0
\end{array}\right.
$$

The statistics $S$ is closely related to Kendall's $\tau$, as given by

$$
\tau=\frac{S}{D}
$$

where

$$
D=\left[\frac{1}{2} n(n-1)-\frac{1}{2} \sum_{j=1}^{p} t_{j}\left(t_{j}-1\right)\right]^{1 / 2}\left[\frac{1}{2} n(n-1)\right]^{1 / 2}
$$

According to Hirsch et al. [42], the seasonal Mann-Kendall statistic, $\hat{S}$, for the entire series is calculated according to

$$
\hat{S}=\sum_{g=1}^{m} S_{g}
$$

For the Sen's slope [46], a set of linear slopes is calculated as follows:

$$
d_{k}=\frac{X_{j}-X_{i}}{j-i}
$$

for $(1 \leq i<j \leq n)$, where $d$ is the slope, $X$ denotes the variable, $\mathrm{n}$ is the number of data points, and $i$ and $j$ are the indices. Sen's slope is then calculated as the median from all slopes; $b=$ Median $d_{k}$. The intercepts are computed for each timestep $t$, as given by:

$$
a_{t}=X_{t}-b * t
$$

The seasonal Sen's slope is calculated as follows:

$$
d_{i j k}=\frac{X_{i j}-X_{i k}}{j-i}
$$

for each $\left(x_{i j}, x_{i k}\right)$ pair, $i=1,2, \ldots, m$, where $1 \leq k \leq j \leq n_{i}$ and $n_{i}$ is the number of known values in the $i$ th season. The seasonal slope estimator is the median of the $d_{i j k}$ values. A p-value of < 0.5 at $95 \%$ confidence indicates a statistical trend. A positive value for the Kendall statistic (S) indicates an increasing trend, and a negative value indicates a decreasing trend. To investigate the extent of trends in relation to the Mann-Kendall test, the Sen's slope and the seasonal Sen's slope (the seasonal Kendall slope estimator) were obtained [42, 46, 47]. Data were constructed by month and the analyses were performed using the statistical program $\mathrm{R}$ (ver.3.6.1).

\subsection{Measurement of Air and Water Temperature in the Influent Stream of Lake Paldang}

Together with the air temperature data from the Yangpyeong Weather Station, water temperature data for the influent streams of Lake Paldang were gathered from the automated water quality monitoring stations installed at Yangpyeong, Gapyeong, and Gyeongancheon (Table S1, Fig. 1). To compare the three locations, water temperature data measured at 5-minute intervals between 2015 and 2018 were obtained from each station [41], and the data were converted to measurements of the daily mean water temperature. The depth of the water temperature measurements was $2 \mathrm{~m}$ at Yangpyeong and Gyeongancheon and $4 \mathrm{~m}$ at Gapyeong. Because the open water temperature data had already undergone screening and confirmation to remove abnormal values, separate data pre-processing was not performed.

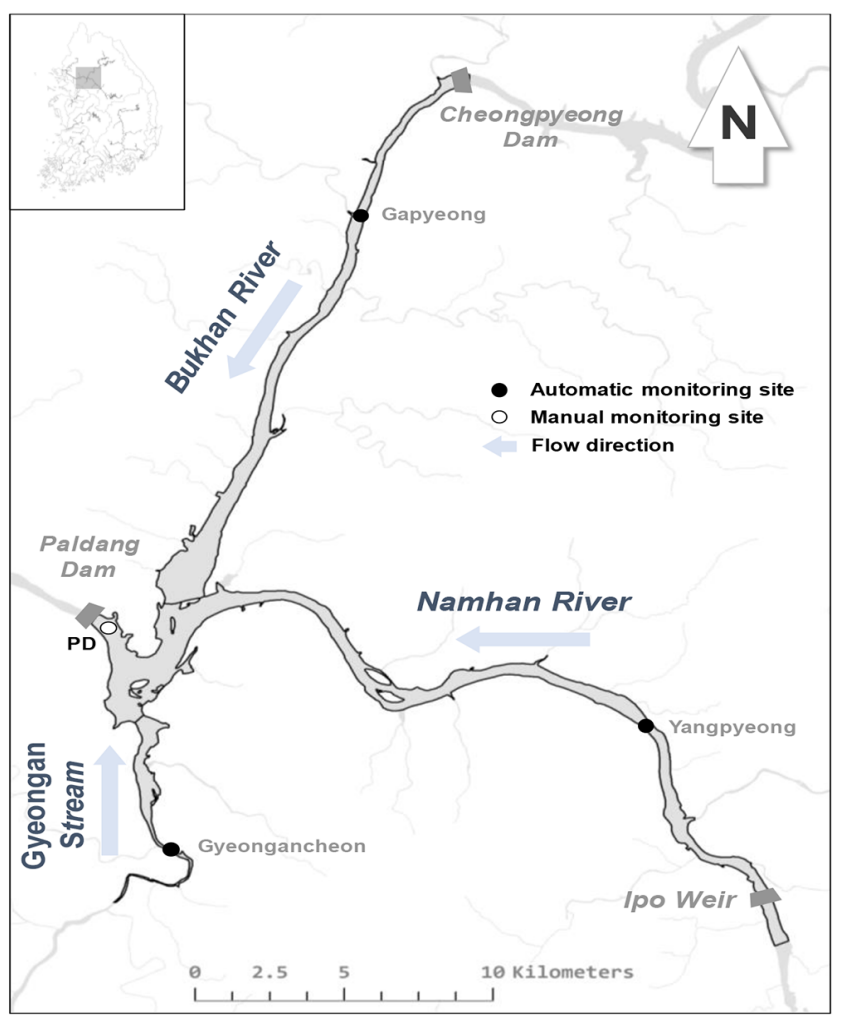

Fig. 1. Major influent river and stream to Lake Paldang and the water temperature monitoring sites.

\subsection{Measurement of Surface Water Temperature at Lake Paldang}

To examine the relationship between air and water temperatures at Lake Paldang, continuous water temperature data were used. Surface water temperature data measured at the PD between May 13th and June 16th, 2016 and between April 5th and July 3rd, 2018 were used to determine the daily mean water temperature. In addition, to understand the water temperature distribution based on the annual isothermal distribution at the $\mathrm{PD}$, water temperature data measured weekly at 1-m intervals between 2013 and 2018 were compared. 


\subsection{Water Temperature Hysteresis at Lake Paldang Using a Numerical Model}

To acquire continuous data for water temperature of all layers of Lake Paldang, considering water temperature changes by depth, a numerical model was constructed based on the EFDC-NIER model used in the Water Quality Forecasting System (National Institute of Environmental Research). The Environmental Fluid Dynamics Code (EFDC) is a numerical model developed by the Virginia Institute of Marine Science and managed by the U.S. Environmental Protection Agency (EPA). It is used for multidimensional interpretation of hydrodynamics, sediment transport, warm/cool water, total maximum daily load (TMDL), and water quality in various water bodies, including rivers, lakes, marshes, and estuaries. The governing equations include the continuity equation, the horizontal and vertical $(\mathrm{x}, \mathrm{y}, \mathrm{z})$ kinetic equations, the density state equations, transport equations, and the heat balance equation [48, 49].

The Lake Paldang numerical model consists of boundary conditions and is divided into weather conditions and influx and efflux conditions. For the weather conditions, data from the Yangpyeong Weather Station were used. Influx consisted of effluent flow from the Bukhan and Namhan Rivers (Cheongpyeong Dam and Ipo Weir), tributary streams (Jojong, Guun, Byeokgye, Mukhyeon, Heuk, and Gyeongan streams), and basic environmental facilities (Yangpyeong, Yangseo, Gwangdong, and Gangha). Efflux consisted of efflux from the Paldang Dam power generator and spillway and intake from the tap water source. For the influx volume, data for the efflux volumes from Cheongpyeong Dam and Ipo Weir were used, and for the flow volume from influent streams, water level-flow volume relationship curves for each river were used to calculate flow volume based on water level data from the water level monitoring stations. For influent streams without water level data, it was estimated using the basin area ratio. For the water level data and the effluent flow volume from Paldang Dam, Cheongpyeong Dam, and Ipo Weir, data provided by the Korea Water Management Information System were used [50]. For the water temperature data for each boundary condition, data from the Water Environment Information System were used [41]. The modeling results of the Lake Paldang numerical model, in comparison to the measured data (water level, water temperature, and water quality) using the absolute mean error (AME) and root mean square error (RMSE), were evaluated (Table S2). The AME and RMSE have the same units as the relevant variable and a result closer to zero indicates better representation of the observed values.

\section{Results and Discussion}

\subsection{Analysis of air and water temperature trends at Lake Paldang}

\subsubsection{Long-term air temperature trends}

Examination of the long-term air temperature changes in the Lake Paldang basin showed an increasing trend in the annual mean temperatures between 1973 and 2018 at the adjacent Yangpyeong Weather Station (Fig. S1). From 1997, the annual mean air temperature exceeded $10^{\circ} \mathrm{C}$, and was continually $\geq 12^{\circ} \mathrm{C}$ after 2014 . On August 1 st, 2018 , the maximum air temperature was $40^{\circ} \mathrm{C}$, which was unprecedentedly high. The monthly mean air temperatures also showed mostly increasing trends from 1973-2018 (Fig. S1 and Fig. 2).

Seasonally, the periods showing differences in air temperature were spring (March-May) and fall (September-November), while there was no considerable difference between July-August and winter (December-February). The lowest temperatures were ob-

$\square$ Jan $\circ$ Feb $\triangle$ Mar + Apr $\times$ May $\diamond$ Jun $\nabla$ Jul $\otimes$ Aug $*$ Sep $\oplus$ Oct $\oplus$ Nov Dec
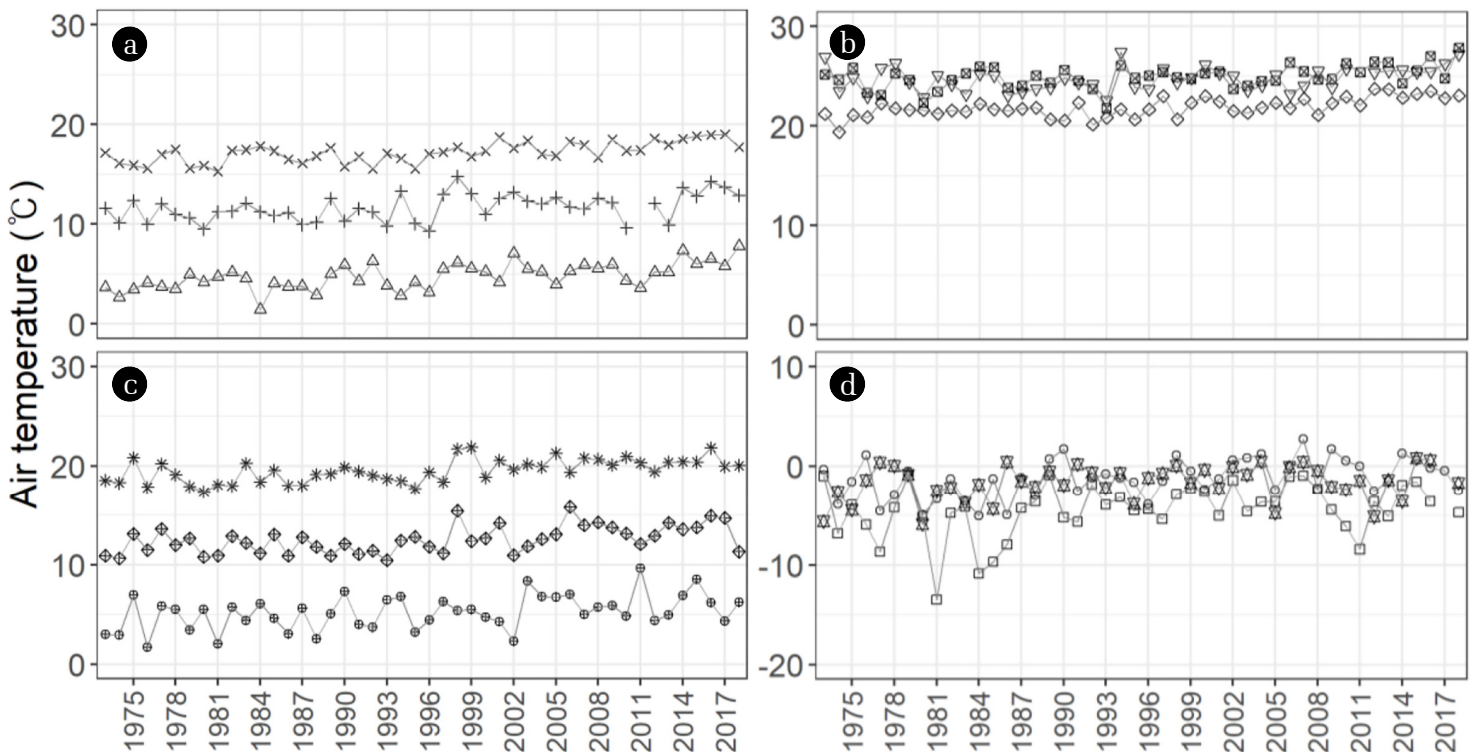

Fig. 2. Comparison of monthly air temperature in Yangpyeong (observed data from Yangpyeong Weather Station, 1973 - 2018) in (a) spring, (b) summer, (c) fall, and (d) winter. 
Table 1. Analysis of Air Temperature Trends at Yangpyeong (observed data from Yangpyeong Weather Station, 1973 - 2018)

\begin{tabular}{|c|c|c|c|c|c|c|c|}
\hline \multirow{2}{*}{\multicolumn{2}{|c|}{ Class }} & \multicolumn{2}{|c|}{ Mean temp. } & \multicolumn{2}{|c|}{ Lowest temp. } & \multicolumn{2}{|c|}{ Highest temp. } \\
\hline & & $\mathbf{S}$ & Slope $\left({ }^{\circ} \mathrm{C} / \mathbf{y r}\right)$ & $\mathbf{S}$ & Slope $\left({ }^{\circ} \mathrm{C} / \mathbf{y r}\right)$ & $\mathbf{S}$ & Slope $\left({ }^{\circ} \mathbf{C} / \mathbf{y r}\right)$ \\
\hline Year (19 & $018)^{1)}$ & $t^{*}$ & 0.05 & $+{ }^{*}$ & 0.08 & $+^{*}$ & 0.02 \\
\hline \multirow{4}{*}{ Season $^{2)}$} & Spring & $+*$ & 0.05 & $+{ }^{*}$ & 0.07 & $+{ }^{*}$ & 0.04 \\
\hline & Summer & $+^{*}$ & 0.04 & $+^{*}$ & 0.07 & + & 0.01 \\
\hline & Fall & $+*$ & 0.06 & $+^{*}$ & 0.10 & + & 0.01 \\
\hline & Winter & $+*$ & 0.05 & $+^{*}$ & 0.09 & + & 0.03 \\
\hline
\end{tabular}

${ }^{*} \mathrm{p}<0.05$

${ }^{1)}$ Seasonal Mann-Kendall test and seasonal Sen's slope, ${ }^{2)}$ Mann-Kendall test and Sen’s slope

served in January.

We used the Mann-Kendall and the seasonal Mann-Kendall tests to investigate statistical trends in the air temperature changes. As shown in Table 1, the majority of trends in air temperature changes showed positive $\mathrm{S}$ values, indicating increasing temperatures; excluding the daily maximum air temperature trends in summer, winter, and fall, the majority of the increasing trends were statistically significant. In terms of the trends related to the seasonal Mann-Kendall test, the seasonal Sen's slope for monthly mean air temperature during the 46 years was $0.05^{\circ} \mathrm{C} / \mathrm{yr}$. The slope was especially steep for the daily minimum air temperature (0.08), which was greater than that for daily maximum air temperature (0.02).

In terms of the Sen's slope, the seasonal mean air temperature in the fall (September-November) increased by $0.06^{\circ} \mathrm{C} / \mathrm{yr}$; however, the increase in the daily minimum air temperature was higher $\left(0.10^{\circ} \mathrm{C} / \mathrm{yr}\right)$. The air temperature in spring (March-May) also increased by $0.05^{\circ} \mathrm{C} / \mathrm{yr}$, which was similar to other seasons. However, the daily maximum air temperature increased by $0.04^{\circ} \mathrm{C} / \mathrm{yr}$, which was higher than in other seasons. These results demonstrate that the air temperature has been increasing during the 46 years included in the study, that the daily minimum air temperature shows an increasing trend, and that the seasonal increases in the daily minimum air temperature were greater in the fall and winter compared to the spring and summer. These trends are similar to those observed in other studies outside Korea [6, 8, 11].

\subsubsection{Comparison of air and water temperature trends at Lake Paldang}

We examined trends in the water temperature at Lake Paldang using weekly water temperature data measured at the PD during the last 14 years, between April 2004 and December 2018, that were provided by the Water Environment Information System [41]. The data consisted of mean weekly water temperature measurements, by depth, unlike the continuously measured air temperature, and were divided by season from March-December, because the water freezes in January and February. When the monthly mean water temperature was compared by year (Fig. 3), the water temperature showed a weaker increasing trend compared to the increase in air temperature, the water temperature in August increased more than in July, and the water temperature also showed an increasing trend in September.

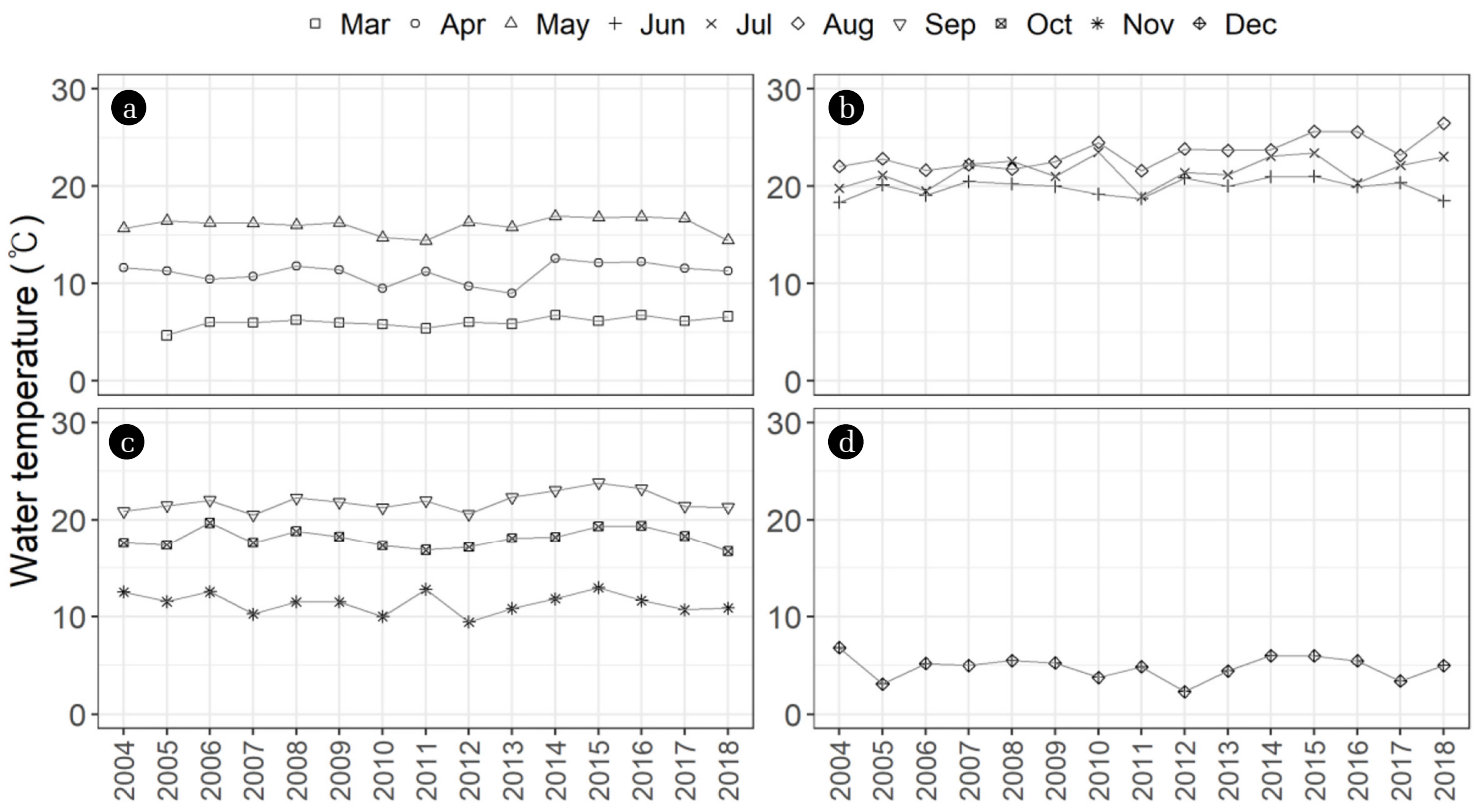

Fig. 3. Comparison of monthly water temperature at Lake Paldang in (a) spring, (b) summer, (c) fall, and (d) winter. 
Table 2. Trend in Air Temperature (mean, lowest, and highest) in the Yangpyeong Area and Water Temperature of Lake Paldang (2004-2018)

\begin{tabular}{|c|c|c|c|c|c|c|c|c|c|c|c|}
\hline \multirow{3}{*}{\multicolumn{2}{|c|}{ Class }} & \multicolumn{6}{|c|}{ Air temp. } & \multicolumn{4}{|c|}{ Water temp. } \\
\hline & & \multicolumn{2}{|c|}{ Mean temp. } & \multicolumn{2}{|c|}{ Lowest temp. } & \multicolumn{2}{|c|}{ Highest temp. } & \multicolumn{2}{|c|}{ Surface } & \multicolumn{2}{|c|}{ Depth average } \\
\hline & & $\mathbf{S}$ & Slope & $\mathbf{S}$ & Slope & S & Slope & $\mathbf{S}$ & Slope & $\mathbf{S}$ & Slope \\
\hline Year $(20$ & $2018)^{1)}$ & $+*$ & 0.06 & + & 0.04 & + & 0.05 & $+*$ & 0.07 & - & - \\
\hline \multirow{4}{*}{ Season $^{2)}$} & Spring & $+^{*}$ & 0.13 & $+^{*}$ & 0.12 & $+*$ & 0.2 & + & 0.06 & + & 0.03 \\
\hline & Summer & + & 0.13 & + & 0.05 & + & 0.1 & $+^{*}$ & 0.29 & $+*$ & 0.13 \\
\hline & Fall & - & -0.2 & - & -0.05 & - & -0.04 & + & 0.01 & + & 0.02 \\
\hline & Winter & - & -0.03 & - & -0.14 & - & -0.05 & + & 0.04 & + & 0.03 \\
\hline
\end{tabular}

${ }^{*} \mathrm{p}<0.05$
${ }^{1)}$ Seasonal Mann-Kendall test and seasonal Sen's slope, ${ }^{2)}$ Mann-Kendall test and Sen's slope

To compare the trends in air and water temperatures during the same period, the trends were analyzed using the Mann-Kendall test and seasonal Mann-Kendall test (Table 2). In terms of air temperature changes in the last 14 years, the seasonal Sen's slope for the monthly mean air temperature was $0.06^{\circ} \mathrm{C} / \mathrm{yr}$, which is slightly higher than that of the last 46 years (0.05). However, by season, the air temperature tended to increase more in spring and summer than in the fall and winter, and were also higher than the increases in air temperature in the spring and summer over the 46 years. This warming rate is consistent with the rapid annual average increase in air temperatures and ocean surface temperatures over a similar time period (1979-2012) [1]. For individual lakes, air and lake temperature trends often diverged, emphasizing the importance of understanding the various factors that control lake heat budgets rather than assuming that lake temperatures will respond similarly to air temperatures [11]. However, this was not considered in this study.

Surface water temperature also showed an increasing trend, the extent of which $\left(0.07^{\circ} \mathrm{C} / \mathrm{yr}\right)$ was higher than that of the air temperature. However, unlike the continuously measured air temperature, water temperature could only be measured weekly and so direct comparisons are difficult. Nevertheless, the increases in the surface water temperature and depth average temperature in summer were relatively large $\left(0.29^{\circ} \mathrm{C} / \mathrm{yr}\right.$ and $0.13^{\circ} \mathrm{C} / \mathrm{yr}$, respectively) with statistical significance $(\mathrm{p}<0.05)$, which is thought to be because, due to the increased air temperature, factors such as solar radiation and tropical nights also affect heat energy transfer and accumulation in water bodies, and these effects are especially strong in lakes and other water bodies with long retention times [14]. Islam et al. [51] used the Air2Stream model, which is a state-of-the-art hybrid river water temperature model relying on heat budgets with a similar formulation and approach as a lake surface temperature model, to investigate changes in air and water temperature between 1950 and 2015 at the Fraser River Basin in British Columbia, Canada, and reported that the summer water temperature increased by approximately $1^{\circ} \mathrm{C}$ in 17 rivers during this time. Kwak et al. [52] modeled water temperature in the Fourchue River in Quebec, Canada using the CMIP5 climate model and RCP 2.6, 4.5, and 8.5 climate change scenarios, and predicted that median water temperatures in June would increase by $0.2-0.7^{\circ} \mathrm{C}$, resulting in favorable temperatures for trout growth and altering the habitats of coldwater species.

\subsection{Changes in air and water temperature in influent streams to Lake Paldang}

\subsubsection{Relationship between air temperature and water temper-} ature

As shown in Fig. 4, when the daily mean water temperatures in Lake Paldang and its influent rivers are compared with the daily mean air temperatures at the Yangpyeong Weather Station, the water temperature shows a smaller increase compared to the air temperature (Air temp. Y.P.). Although there were differences each year, in general, the water temperatures at Gyeongan Stream (Water temp. G.A.) and Namhan River (Water temp. Y.P.) were higher than the air temperature from September to the following February (i.e., when the air temperature was decreasing) and the water temperature showed a similar increase to the air temperature from March onwards. At Bukhan River (Water temp. G.P.), from April or May, the increase in water temperature was slower and smaller than that of the air temperature. Then, entering August, when the air temperature peaked the change in water temperature became similar to that of the air temperature. The rate of increase in the water temperature was slower at Gapyeong due to middle layer efflux from the upstream Cheongpyeong Dam and also a result of measurements being taken at a $4 \mathrm{~m}$ depth. From September, when the air temperature was decreasing, the water temperature at all three locations decreased, but remained higher than the air temperature. For Lake Paldang, the surface layer water temperature was continuously monitored for some time periods in 2016 and 2018, and after conversion to mean daily water temperature the results were similar to Namhan River (Water temp. Y.P.). This is thought to be because, as the colder water from Bukhan River and the warmer water from Namhan River meet at Lake Paldang, the temperature difference led to the formation of a density gradient and the upper layers at the PD, downstream from Lake Paldang, are predominantly composed of less dense water from Namhan River. Research on the effects of temperature on density supports these suggestions [53].

\subsubsection{Water temperature hysteresis in the influent rivers to Lake Paldang}

In addition to air temperature, several other factors affect water temperature; due to the important physical characteristic whereby, water has higher specific heat than air, hysteresis is an important factor affecting water temperature [14, 54]. When air and water 

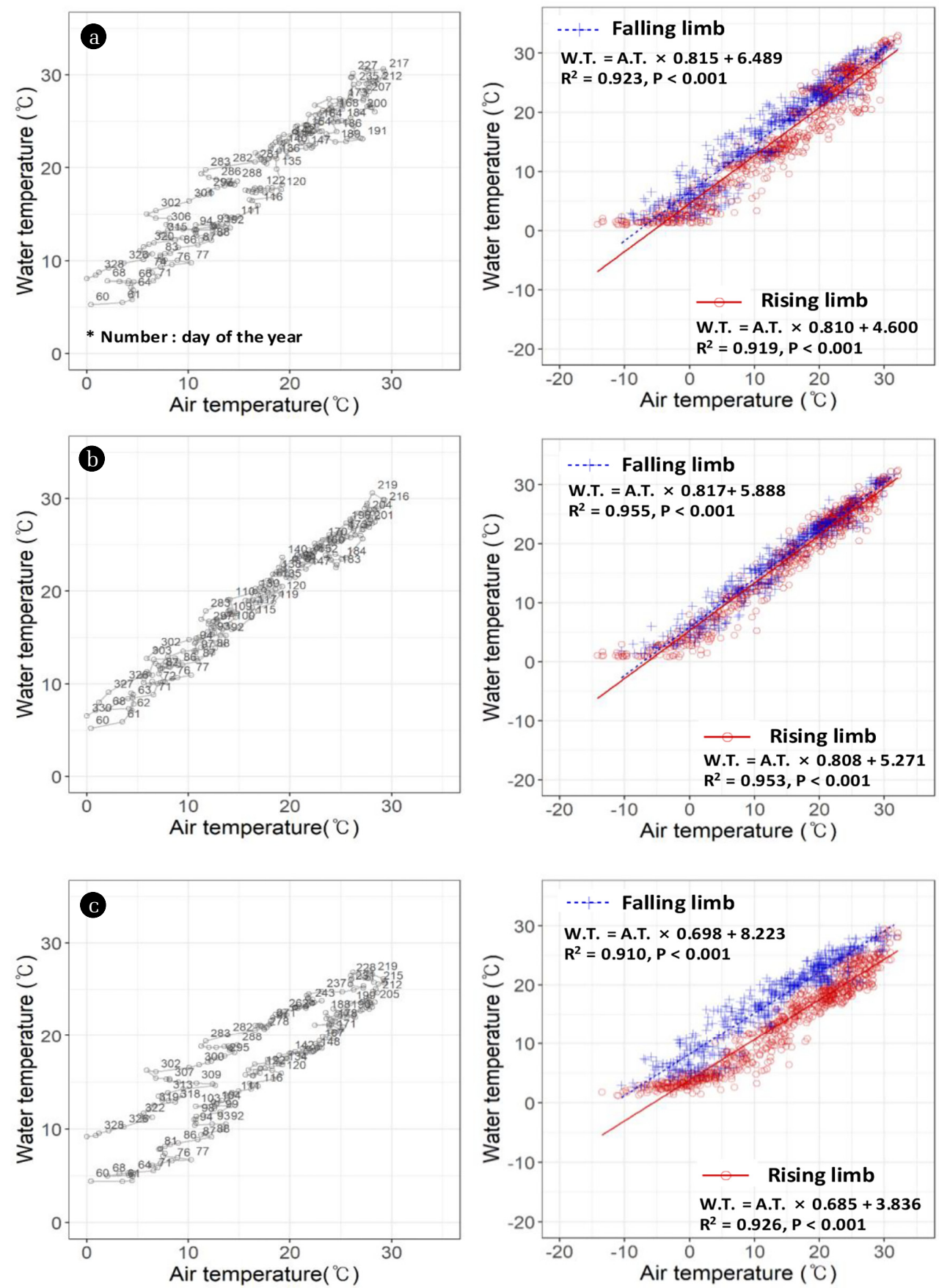

Fig. 4. Relationships between air temperature and water temperature hysteresis in the influent rivers to Lake Paldang: (a) Yangpyeong, (b) Gyeongancheon, and (c) Gapyeong.

temperatures were compared at 10-day intervals (Fig. 4) in the influent rivers to Lake Paldang, the period when air and water temperatures were increasing and the period when they were decreasing can be divided at approximately Day 220. Namhan River and Gyeongan Stream showed similar changes in air and water temperatures both when the water temperature was increasing (rising limb) and when it was decreasing (falling limb). On the other hand, at Gapyeong the increase and decrease of water temperature was delayed compared to the air temperature, and seasonal hysteresis was clearly observed, especially during the falling limb. As described above, the water temperatures at Gyeongancheon and Yangpyeong were measured at a depth of $2 \mathrm{~m}$ while the water temperature at Gapyeong was measured at a depth of 4-5 m. Therefore, while the water temperature closer to the surface at 
Gyeongancheon and Yangpyeong was affected directly by the air temperature, at Bukhan River (Gapyeong) measurements were affected by the low temperature of the river water itself as well as the colder water due to middle layer efflux from Cheongpyeong Dam. In addition, for the effect of influent on water temperature, Webb et al. [28] investigated catchments ranging in size from 2.1-601 $\mathrm{km}^{2}$ using multiple regression analysis representing increasing flow volume and thermal capacity that give rise to reduced water temperatures. This is consistent with previous multivariate analysis of river temperatures [55].

When the data were divided into the rising and falling limbs around mid-August (Day 220) and the correlations between air and water temperatures were compared using daily mean values (Fig. 4), the coefficients of determination were $\geq 0.9$ in most cases, demonstrating strong correlations. Seasonally, rivers in South Korea show slightly lower water temperatures than air temperatures in summer, however, water temperatures in winter have been reported to be higher than air temperatures by up to $10^{\circ} \mathrm{C}$ [25]. For smaller river or stream such as the Gyeongan Stream, the association between water and air temperature is even stronger [37, 56]. At Yangpyeong and Gyeongancheon, the water-to-air temperature ratio was similar in the rising limb and the falling limb (i.e., 0.80-0.82) and it is thought that the majority of shallow rivers will exhibit similar characteristics. Meanwhile, at Gapyeong, the correlation was strong (coefficient of determination, 0.9), however, the water-to-air temperature ratio in the rising/falling limb was around 0.7 , and the intercept values differed between the rising and falling limb, whereby the effects of the middle layer water temperature delayed the decrease in water temperature in the falling limb, showing hysteresis. The specific heat of water is higher than that of air, and water temperature shows hysteresis compared to air temperature. Therefore, in terms of the scale of a water body, a lake that has absorbed more heat energy can be predicted to show greater hysteresis between air and water temperature, and the water temperature across all depths can be expected to show a greater delay than the surface layer $[57,58]$.

\subsection{Changes in Air and Water Temperature at Lake Paldang}

When continuous water temperature data from the surface layer at
Paldang Dam (Fig. S2, Water temp. P.D.) in 2016 and 2018 were converted to daily mean water temperatures and compared with the air temperatures, the patterns were generally similar to the Namhan River (Yangpyeong), where the water temperature was generally higher than the air temperature. When the air and water temperature were compared at 10-day intervals between April and September, the surface layer water temperature at Lake Paldang increased at a similar level to the air temperature during the rising limb, whereas there was no clear trend in the falling limb (up to September) (Fig. 5).

As shown in Fig. 5, the ratios between water and air temperature (slope) at Lake Paldang were similar to Yangpyeong in the rising limb and similar to Gapyeong in the falling limb. This is thought to be due to the fact that the water temperature in the rising limb was higher in Namhan River than in Bukhan River, creating a difference in the water density that resulted in water from Namhan River being located in the upper layers. Meanwhile, in the falling limb, hysteresis in the lake causes the water temperature to decline more slowly. When a lake is deep and is connected to water bodies that have different temperatures (like Lake Paldang), differences in water temperature develop by depth due to density currents, resulting in stratification [53]. Because this also influences the mixing of water bodies, the use of continuous data from different depths is very important. Stefan and Preud'homme [27] performed a linear correlation analysis of water and air temperature in 11 rivers in the Mississippi River basin in the central US. They derived the general equations W.T $=5.0+0.75 \times$ A.T for the daily water temperature and W.T $=2.9+0.86 \times$ A.T for the weekly water temperature and reported that the time lag between water and air temperature occurred at a scale of several hours to several days, depending on the river size (including depth and breadth) and that an increase in the river depth was associated with a longer time lag. The daily water-to-air temperature ratios in the influent rivers to Lake Paldang in the rising limb were generally similar to those in the falling limb (i.e., 0.81-0.82).

In front of PD site, the water depth is $>20 \mathrm{~m}$, and Fig. S3 shows the isothermal distribution maps by depth from 2013-2018. Changes in water temperature affect water quality and algae outbreaks in bodies of water [31, 59], and the times of year during
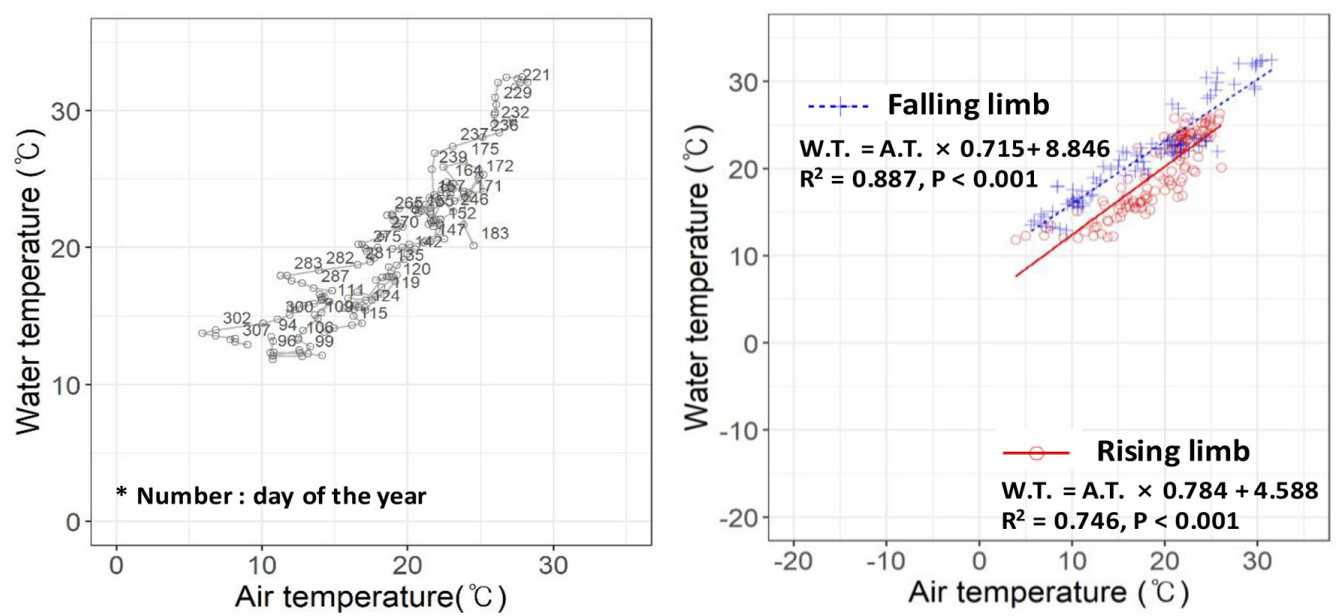

Fig. 5. Relationship between air temperature and surface layer water temperature at Lake Paldang. 

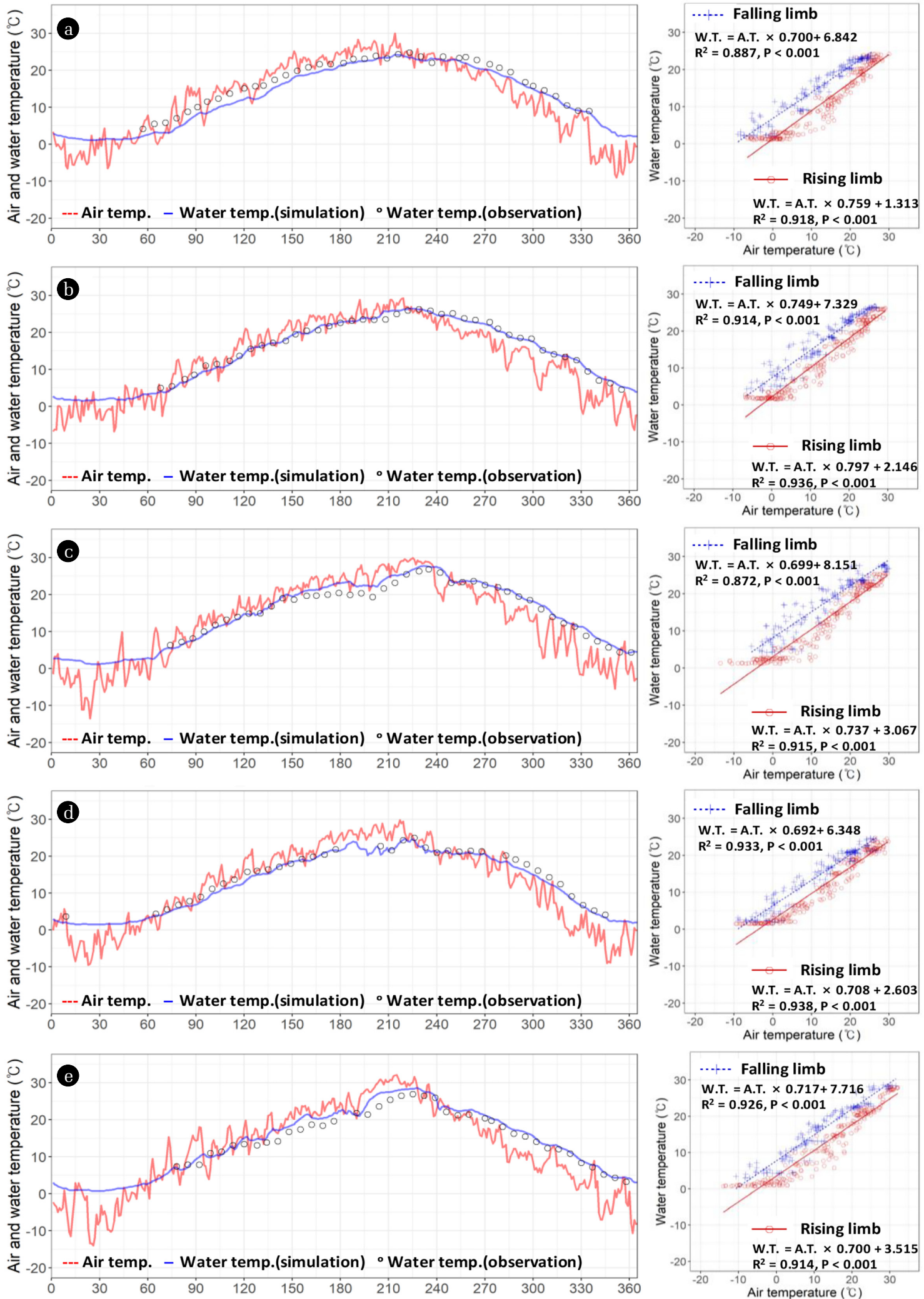

Fig. 6. Yearly variation between air and water temperatures of the whole depth of Lake Paldang, according to model simulation, in (a) 2014, (b) 2015, (c) 2016, (d) 2017, (e) 2018. 
which large changes in water temperature occurred were March (i.e., after thawing), June, and July-September. In March, the air temperature began to increase after thawing, in June there was a large temperature increase, and in July and August high temperatures persisted, affecting cyanobacteria abundance [31, 59]. In terms of the times when the water temperature exceeded $25^{\circ} \mathrm{C}$ (Fig. 6), high water temperatures persisted for the longest duration in 2014, however, the maximum depth was around $10 \mathrm{~m}$, while in 2015 , temperatures $\geq 25^{\circ} \mathrm{C}$ were observed up to a depth of 17 m. In 2016 and 2018, high water temperatures $\left(\geq 25^{\circ} \mathrm{C}\right)$ were observed at depths up to $19 \mathrm{~m}$ and $20 \mathrm{~m}$, respectively. Thus, the distribution of water temperature by depth differed each year and the air temperature affected not only the surface layer but also influenced changes in the water temperature at different depths. In particular, cyanobacteria appear due to a combination of increasing water temperatures, competition and predation, light, retention time, low washout rate, nutritive salts, strong vertical stratification, air temperature, and stabilization of water layers [31]. Of these factors, air temperature is closely related to increasing water temperatures, light, stratification, and stabilization. When stratification occurs, if mixing between layers ceases and the water body of water stabilizes, conditions become favorable for cyanobacterial growth. If stratification persists for a long time, or all layers show long-term high temperatures, the water body stabilizes which can result in long-lasting cyanobacterial blooms [59]. Water temperature is one of the most important determining factors for physical and ecological processes and it is also a governing factor for fish growth and spawning [17].

\subsection{Analysis of Water Temperature Hysteresis Using a Numerical Model of Lake Paldang}

To investigate water temperature hysteresis, we used a numerical model to acquire continuous daily data for water temperature. The AMEs for the modeled water temperature values and the actual measured values between 2014 and 2018 were $0.6-1.8^{\circ} \mathrm{C}$ and the RMSEs were $0.7-1.8^{\circ} \mathrm{C}$, demonstrating the reproducibility of water temperature changes in Lake Paldang. Daily data (excluding the period with subzero air temperatures to account for phase changes in water) were divided into the rising limb and the falling limb and regression analyses were performed on the air and water temperatures at the PD (Fig. 6, Table S3). At a significance level of $\mathrm{p}$ $<0.010$, the coefficient of determination was usually $\geq 0.9$, except for data from the falling limb of 2016 where the coefficient of determination was 0.89 . This means that the air temperature had strong explanatory power for analyzing water temperature changes, and in particular, the rising limb showed a stronger relationship between air and water temperature than the falling limb.

Ratios between the mean water temperature by depth and the air temperature at Lake Paldang were similar in the rising limb and the falling limb, at $0.71-0.80$ and $0.69-0.75$, respectively. Conversely, the intercept was 1.31-3.52 in the rising limb and 6.35-8.15 in the falling limb (representing an increase of around $4-5^{\circ} \mathrm{C}$ ) and the decrease in water temperature in the falling limb was more delayed than the increase in the water temperature in the rising limb. The differences in the intercept between the rising and falling limbs were large in 2014, 2015, and 2016, i.e., when the air temperature was high. For large water bodies (such as lakes and marshes), after a, increase in water temperature, providing there is no water exchange due to heavy rain [32], even when the air temperature begins to fall there is a delay before the water temperature also declines [26]. In particular, if there is a delay in the decrease in the water temperature at the start of the falling limb, biological activity in the water persists, which can lead to the continuation of algae outbreaks [31, 59]. Generally, an increase in water temperature leads to major cyanobacterial proliferation, however, Elliott [60] reported that cyanobacteria are approximately as sensitive to water temperature and retention time as other algae species, and that higher water temperature and longer retention time are associated with prominent cyanobacterial proliferation. Compared to other species, cyanobacteria show more acceleration in their growth rate with higher water temperatures. When the temperature of the surface layer increases a process of stratification begins, and if the summer becomes longer the duration of stratification is extended, resulting a longer period of stabilization [34], which is a factor in the persistent appearance of cyanobacteria. Therefore, when the air temperature increases, due to water temperature hysteresis in lakes and marshes, the water temperature declines more slowly, and the longer period of high water temperatures increases the possibility of persistent cyanobacteria blooms which are well adapted to high water temperatures.

\section{Conclusions}

Based on long-term air and water temperature data for Lake Paldang, the largest water source in South Korea, the relationship between air and water temperature was investigated by studying hysteresis of the water temperature and using a numerical model. Over 46 years, the air temperature in the Lake Paldang drainage basin increased by $0.05^{\circ} \mathrm{C} / \mathrm{yr}$ (seasonal Sen's slope), and the daily minimum air temperature increased by $0.08^{\circ} \mathrm{C} / \mathrm{yr}$, meaning that the increase in minimum air temperature was responsible for the increase in annual air temperature. In terms of air temperature changes in the last 15 years, the seasonal Sen's slope for the monthly mean air temperature was $0.06^{\circ} \mathrm{C} / \mathrm{yr}$, which is slightly higher than that of the last 46 years $\left(0.05^{\circ} \mathrm{C} / \mathrm{yr}\right)$. Analysis of the water temperature using a numerical model showed that the coefficient of determination was $\geq 0.86$. During the period when the water temperature was increasing (rising limb), the ratios of the air temperature to the water temperature $(0.71-0.77)$ were relatively close to that during the time when the water temperature was decreasing (falling limb; $0.70-0.76)$. However, the intercept values were $0.13-3.52$ in the rising limb and 6.62-7.78 in the falling limb, and, therefore, there was a $4-5^{\circ} \mathrm{C}$ increase in temperature. In particular, in 2015, 2016, and 2018, the intercept values in the falling limb were $\geq 7$, exhibiting hysteresis in which high water temperatures were slow to decline. Lake Paldang is a river-type reservoir with a shorter retention time than other large artificial lakes. However, Lake Paldang exhibits more water temperature hysteresis than its influent rivers. The rising and falling limbs did not show a large difference in the extent of water temperature change (i.e., the slope) at Lake Paldang. However, the water temperature has not rapidly decreased and the duration of the decrease is longer due to hysteresis. In this 
study, water temperature hysteresis using long-term data may contribute to the management of water quality and the ecosystem of Lake Paldang.

\section{Acknowledgment}

This research was supported by the National Institute of Environmental Research (NIER) [grant number NIER-2017-0101-079], funded by the Ministry of Environment (MOE) of the Republic of Korea.

\section{Author Contributions}

Y.S.J. (Director) conducted data analysis and wrote the manuscript R.I.G. (Researcher) conducted data analysis and numerical design. P.M.J. (Researcher) conducted data analysis and numerical design. I.J.K. (Researcher) wrote and revised the manuscript.

\section{References}

1. Stocker TF, Qin D, Plattner GK, et al. Climate change 2013: The physical science basis. Contribution of working group I to the fifth assessment report of the intergovernmental panel on climate change 2013;1535.

2. Jones PD, New M, Parker DE, Martin S, Rigor IG. Surface air temperature and its changes over the past 150 years. Rev. Geophys. 1999;37:173-199.

3. Czernecki B, Ptak M. Impact of global warming on lake surface water temperature in Poland-the application of empirical-statistical downscaling. J. Limnol. 2018;1971-2100.

4. National Oceanic and Atmospheric Administration (NOAA), National Centers for Environmental Information, State of the Climate: Grobal Climate Report for Annual 2017, published online January 2018, retrieved on July 4. 2018 [Internet] [cited 2 January 2020]. Available from http://www.ncdc.noaa.gov/sotc/ global/201713

5. National Institute of Meteorological Sciences (NIMS), Climate change of 100 years in Peninsula, 2018, 11-1360620-000132-01 [Korean Literature]

6. Firoozi F, Roozbahani A, Bavani AM. Developing a framework for assessment of climate change impact on thermal stratification of dam reservoirs. Int. J. Environ. Sci. Technol. 2020;17:2295-2310.

7. Austin JA, Colman SM. Lake Superior summer water temperatures are increasing more rapidly than regional air temperatures: A positive ice-albedo feedback. Geophys. Res. Lett. 2007;34:L06604.

8. Virdis SG, Soodcharoen N, Lugliè A, Padedda BM. Estimation of satellite-derived lake water surface temperatures in the western Mediterranean: Integrating multi-source, multi-resolution imagery and a long-term field dataset using a time series approach. Sci. Total Environ. 2020;707:135567.

9. Schneider P, Hook SJ. Space observations of inland water bodies show rapid surface warming since 1985. Geophys. Res. Lett. 2010;37:L22405.

10. Kim BS, Hong SJ, Lee HD. The potential effects of climate change on streamflow in rivers basin of Korea using rainfall elasticity. Environ. Eng. Res. 2013;18:9-20.

11. O'Reilly CM, Sharma S, Gray DK, Hampton SE, Read JS, Rowley RJ, Schneider P, Lenters JD, McIntyre PB, Kraemer BM. Rapid and highly variable warming of lake surface waters around the globe. Geophys. Res. Lett. 2015;42:773-781.

12. Piccolroaz S, Healey N, Lenters J, Schladow S, Hook S, Sahoo $\mathrm{G}$, Toffolon M. On the predictability of lake surface temperature using air temperature in a changing climate: A case study for Lake Tahoe (USA). Limnol. Oceanogr. 2018;63:243-261.

13. Piccolroaz S, Toffolon M, Majone B. The role of stratification on lakes' thermal response: The case of Lake S uperior. Water Resour. Res. 2015;51:7878-7894.

14. Gossiaux A, Jabiol J, Poupin P, Chauvet E, Guérold F. Seasonal variations overwhelm temperature effects on microbial processes in headwater streams: insights from a temperate thermal spring. Aquat. Sci. 2019;81:1-11.

15. Park J, Kim K, Cho C, Kang M, Kim B. Spatio-temporal characteristics of air and water temperature change in the middle reach of the Nakdong River. J. Environ. Policy Admin. 2016;9:233-253.

16. Hassan WH, Nile BK, Al-Masody BA, Hassan WH, Nile BK, Al-Masody BA. Climate change effect on storm drainage net works by storm water management model. Environ. Eng. Res. 2017;22:393-400

17. Dugdale SJ, Curry RA, St-Hilaire A, Andrews SN. Impact of future climate change on water temperature and thermal habitat for keystone fishes in the lower Saint John River, Canada. Water Resour. Manag. 2018;32:4853-4878.

18. Collas FP, van Iersel WK, Straatsma MW, Buijse AD, Leuven RS. Sub-daily temperature heterogeneity in a side channel and the influence on habitat suitability of freshwater fish. Remote Sens. 2019;11:2367.

19. Besson M, Vandeputte Mv, Van Arendonk J, Aubin J, De Boer I, Quillet E, Komen H. Influence of water temperature on the economic value of growth rate in fish farming: the case of sea bass (Dicentrarchus labrax) cage farming in the Mediterranean. Aquaculture 2016;462:47-55.

20. Szumińska D, Czapiewski S, Goszczyński J. Changes in Hydromorphological Conditions in an Endorheic Lake Influenced by Climate and Increasing Water Consumption, and Potential Effects on Water Quality. Water 2020;12:1348.

21. Carter T, Hulme M, Lal M. IPCC-TGCIA Guidelines on the use of scenario data for climate impact and adaptation assess ment, version 1. IPCC, Task Group on Scenarios for Impact Assessment 1999.

22. Houghton JT, Ding Y, Griggs D, et al. Climate Change 2001: The Scientific Basis, Cambridge Uni, in, Press, 2001.

23. Zhao C, Yang Y, Yang S, et al. Predicting future river health in a minimally influenced mountainous area under climate change. Sci. Total Environ. 2019; 656:1373-1385.

24. Webb B. The relationship between air and water temperatures for a Devon river. Rep. Trans. Devon. Ass. Advmt. Sci. 1987;119 197-222.

25. An JH, Lee KH. Correlation and hysteresis analysis of air-water temperature in four rivers: preliminary study for water temperature prediction. J. Environ. Pol. 2013;12:17-32.

26. Jeppesen E, Iversen TM. Two simple models for estimating 
daily mean water temperatures and diel variations in a Danish low gradient stream. Oikos 1987;149-155.

27. Al Qatarneh GN, Al Smadi B, Al-Zboon K, Shatanawi KM. Impact of climate change on water resources in Jordan: a case study of Azraq basin. Appl. Water Sci. 2018;8:50.

28. Webb B, Clack P, Walling D. Water-air temperature relationships in a Devon river system and the role of flow. Hydrol. Process. 2003;17:3069-3084.

29. Zohary T, Flaim G, Sommer U. Temperature and the size of freshwater phytoplankton. Hydrobiologia 2020:1-13.

30. Flaim G, Obertegger U, Anesi A, Guella G. Temperature-induced changes in lipid biomarkers and mycosporine-like amino acids in the psychrophilic dinoflagellate $\mathrm{P}$ eridinium aciculiferum. Freshwater Biol. 2014;59:985-997.

31. Paerl HW, Gardner WS, Havens KE, Joyner AR, McCarthy MJ, Newell SE, Qin B, Scott JT. Mitigating cyanobacterial harmful algal blooms in aquatic ecosystems impacted by climate change and anthropogenic nutrients. Harmful Algae 2016;54:213-222.

32. Son JY, Park JR, Noh HR, Yu SJ, Im JK. Seasonal characteristics of thermal and chemical stratification in Lake Paldang. J. Korean Soc. Water Environ. 2020;36:1-13.

33. Ficker H, Luger M, Gassner H. From dimictic to monomictic: empirical evidence of thermal regime transitions in three deep alpine lakes in Austria induced by climate change. Freshwater Biol. 2017;62:1335-1345.

34. Paerl HW, Paul VJ. Climate change: links to global expansion of harmful cyanobacteria. Water Res. 2012;46:1349-1363.

35. Paerl HW, Havens KE, Hall NS, et al. Mitigating a global expansion of toxic cyanobacterial blooms: confounding effects and challenges posed by climate change. Mar. Freshwater Res. 2020:71;579-592.

36. Ministry of Environment. Water environmental monitoring network operation plan. 2019. p. 1-58.

37. Sharma S, Walker SC, Jackson DA. Empirical modelling of lake water-temperature relationships: a comparison of approaches. Freshwater Biol. 2008;53:897-911.

38. Thiery W, Stepanenko VM, Fang X, et al. LakeMIP Kivu: evaluating the representation of a large, deep tropical lake by a set of one-dimensional lake models. Tellus A 2014;66:21390.

39. Wahl B, Peeters F. Effect of climate changes on stratification and deep-water renewal in Lake Constance assessed by sensitivity studies with a 3D hydrodynamic model. Limnol. Oceanogr. 2014;59:1035-1052.

40. Korea Meteorological Administration, Weather information service [Internet] [cited 2 January 2020]. Available from : http://www.kma.go.kr.

41. Ministry of Environment. Water environment information system [Internet] [cited 2 January 2020]. Available from : http://www.water.nier.go.kr.

42. Mann HB. Nonparametric tests against trend. Econometrica 1945;13:245-259.
43. Kendall M. Rank Correlation Methods; Charles Griffin: London, 1975.

44. Hirsch RM, Slack JR, Smith RA. Techniques of trend analysis for monthly water quality data. Water Resour. Res. 1982;18: 107-121.

45. Helsel DR, Hirsch RM. Statistical methods in water resources. Amsterdam: Elsevier; 1992. p. 323-344.

46. Sen PK. Estimates of the regression coefficient based on Kendall's tau. J. Am. Stat. Assoc. 1968;63:1379-1389.

47. Yu Y-S, Zou S, Whittemore D. Non-parametric trend analysis of water quality data of rivers in Kansas. J. Hydrol. 1993;150: 61-80.

48. Ji ZG, Hydrodynamics and water quality: modeling rivers, lakes, and estuaries. John Wiley \& Sons; 2017.

49. Tetra Tech I. The Environmental Fluid Dynamics Code Theory and Computation Volume 1: Hydrodynamics and Mass Transport. Tetra Tech, Fairfax, Virginia; 2007.

50. Ministry of Environment. Water management information system [Internet] [cited 2 January 2020]. Available from : http://www.wamis.go.kr.

51. Islam SU, Hay RW, Déry SJ, Booth BP. Modelling the impacts of climate change on riverine thermal regimes in western Canada's largest Pacific watershed. Sci. Rep. 2019;9:1-14.

52. Kwak J, St-Hilaire A, Chebana F, Kim G. Summer season water temperature modeling under the climate change: case study for Fourchue River, Quebec, Canada. Water 2017;9:346.

53. Moreira S, Schultze M, Rahn K, Boehrer B. A practical approach to lake water density from electrical conductivity and temperature. Hydrol. Earth Syst. Sc. 2016;20.

54. Erickson TR, Stefan HG. Linear air/water temperature correlations for streams during open water periods. J. Hydrol. Eng. 2000;5:317-321.

55. Hockey J, Owens I, Tapper N. Empirical and theoretical models to isolate the effect of discharge on summer water temperatures in the Hurunui River. J. Hydrol. 1982;1-12.

56. Livingstone DM, Dokulil MT. Eighty years of spatially coherent Austrian lake surface temperatures and their relationship to regional air temperature and the North Atlantic Oscillation. Limnol. Oceanogr. 2001;46:1220-1227.

57. Edmundson J, Mazumder A. Regional and hierarchical perspectives of thermal regimes in subarctic, Alaskan lakes. Freshwater Biol. 2002;47:1-17.

58. Kettle H, Thompson R, Anderson NJ, Livingstone DM. Empirical modeling of summer lake surface temperatures in southwest Greenland. Limnol. Oceanogr. 2004;49:271-282.

59. Wells ML, Trainer VL, Smayda TJ, et al. Harmful algal blooms and climate change: learning from the past and present to forecast the future. Harmful algae 2015;49:68-93.

60. Elliott JA. The seasonal sensitivity of cyanobacteria and other phytoplankton to changes in flushing rate and water temperature. Glob. Change Biol. 2010;16:864-876. 